ing in a consortium representing a capital of upwards of I milliard of marks.

In addition to the Haber process, ammonia is being produced by the cyanamide method. The factories employing this process are mainly erected in the neighbourhood of lignite deposits, in localities furnishing supplies of natural gas, or where hydraulic power is available. Before the war the principal factories were the Bayerische Stickstoffwerke at Trostberg, the A.G. für Stickstoffdünger at Knapsack, and the Mitteldeutsche Stickstoffwerke at Gross-Kayna (Geiseltal). The development of the cyanamide industry is encouraged by the Government. The Bavarian Company received a subsidy of 40 million marks and undertook the erection of two large factories in proximity to deposits of coal and lignite. These were completed towards the end of November, 19I5. The net profits of the Bayerische Stickstoffwerke in $1914-15$ were 653,185 marks; in I9I6-I7 they were $1,547,261$ marks. In 1915 the company at Knapsack raised its capital from 3 to 8 million marks. In 1916 the total production of cyanamide had increased to 400 , 000 tons, practically a hundred times greater than it was in 1913. There is no doubt that it has since been considerably augmented.

Such are the means by which Germany has meanwhile rendered herself independent of Chile saltpetre, or, indeed, of any outside source of nitric acid or ammonia, and has provided herself with one of the essential munitions of war. So absolutely necessary is the production of nitric acid that, in its absence, no army could hold together for a week under modern conditions. This enormous development of the synthetic production of ammonia and nitric acid is of great economic interest, and is bound to have a profound effect on industry after the war. The economic aspect of the matter, however, does not now concern us. We may return to its consideration on another occasion.

Scarcely less important, in view of the war, is the problem of sulphur and sulphuric acid, to which we have already directed attention. Our blockade practically suppressed all German importation of pyrites, of which in time of peace she received upwards of ro million quintals, $8 \frac{1}{2}$ millions coming from Spain. Germany was thus restricted to her own poor deposits in Thuringia, in the Lahn basin, at Tessenberg in Bavaria, and at Meggen in Westphalia. The important deposits of cupreous pyrites of Styria and Hungary were at once exploited, as were those of sulphur in Anatolia. The roasting of blende at Vieille-Montagne and in Silesia had already furnished considerable quantities of sulphuric acid before the war : by intensive working the yield was considerably increased. Processes like those of Schaffner and Helbig and of Chance and Claus were worked on a large scale. The Badische Company utilised the method of Walther Feld, in which crude coalgas is made to yield its ammonia and sulphur in the form of ammonium sulphate. This is effected by agitating the gas with a solution of ammonium tetrathionate, which absorbs the hydrogen sulphide and ammonia, giving ammonium sulphate, hyposulphite, and free sulphur. By boiling the ammonium tetrathionate with the hyposulphite, ammonium sulphate, sulphurous acid, and sulphur are obtained. By making the two last-named substances react upon the hyposulphite arising from the purification, the tetrathionate is regenerated. The Badische Company has also attempted to prepare sulphuric acid from gypsum or anhydrite, of which Germany has considerable deposits, by roasting the gypsum either alone or mixed with coke, whereby it is transformed into calcium sulphide, which can then be treated by any of the established sulphur-recovery processes, or converted into lime or sulphurous acid, to be either utilised in the manufacture of wood-pulp for papermaking or transformed into oil of vitriol.

So important is sulphuric acid for the purposes of war that its production is controlled by a War Committee, and the Society for the Production of War Chemicals has created a special section known as the Department of the Administration of Sulphur. As in the case of other chemical products, the manufacture and sale are regulated, and fixed prices have been legalised.

In a subsequent article we propose to show how Germany has dealt with the problems of combustibles, metals, alcohol, oils, fats, soap and glycerin, textiles, wood and wood-pulp, caoutchouc, turpentine and lubricants, food, fodder and manures-all of which are more or less essential to her, and of which she has been largely deprived by her own action in embarking upon a war which will prove her ruin.

\section{MEDICAL EDUCATION IN ENGLAND 1}

THE issue of the modestly named paper before us marks a new stage in the relation of the State to English education. In no merely official style, but with the breadth and freshness of outlook proper to a prophet of reform, Sir George Newman reviews the "undone vast" in the training of medical practitioners for national service. He gives due credit to the great achievements of English medicine, as they have been wrought out by private enterprise, for until comparatively late years the schools of medical craftsmanship were in their essence proprietary, and their system was but a modified apprenticeship. In Scotland doctors were trained at the universities and caught something of the university spirit. The last generation has seen a change, in provincial England at least: London is still in the stage of painful emergence. When grants to the medical schools were first made by the Board of Education in 1908 , the State necessarily assumed the duty of watching their application to productive uses. A universities branch of the Board was formed, and Sir George Newman became its medical

1 "Snme Notes on Medical Education in England.". A Memorandum addressed to the President of the Board of Education i.y Sir George Newman, K.C.B., Chief Medical Officer, Principal Assistant Secretary of the Board of Education, etc. Presented to both Houses of Parliament by Price gd. NO. 2552 , VOL. IO2] 
assessor. His admirable contribution to "Reconstruction " is the fruit of his official surveys of the present state and future needs of the English schools.

The relation of the community to the doctor has altered. The latter is no longer merely a private craftsman dealing with private clients. Before the war called the main body of practitioners into war service, the State as such claimed the whole-time or part-time service of some 20,000 of them, and imposed heavy civic responsibilities upon the rest. The doctors were called to a wider ministry than heretofore; the State by implication must needs concern itself with the question of seeing that they were fitted to serve it. In the words of the paper, "medicine has become a quasi-public profession; . . . the citizen, as legislator and as taxpayer no less than as patient, is interested in the maintenance of a high standard of medical education. ... The commonwealth does not require two standards of medical man. . . . All medical education should be fundamentally one and the same in regard to basis, technique, and spirit." Sir George Newman without hesitation pronounces that there is only one education which will meet the requirements of the nation; "in a word, it is a university education in medicine. And the foundation of such an education is science."

$\mathrm{He}$ is well aware that the present five years' curriculum is overloaded; but it can be lightened to some extent when all secondary schools teach science efficiently. The student would not, as now, begin his medical course ignorant of the essential propædeutic of chemistry, physics, and biology. If the elements of these were already familiar to him, the university professors of the first-year stage might limit themselves to senior courses on the medical bearings of these subjects. Anatomy and physiology, sow taught to an everincreasing degree in the true scientific spirit, should be more closely related with clinical medicine and surgery. The laboratory and the demonstration-lecture must displace the "systematic" lecture. Pharmacology, from which "materia medica" and pharmacy may now be severed, should link up physiology with clinical therapeutics, and have its laboratories and special staffs. Therapeutics should constitute a distinct department, in direct relation with the hospital ward and out-patient room. Pathology, which has of late "come to its own," must all over the country have its hospital "institute," under its own professor and assistants, and be worked as an indispensable factor in ward-work, and planned on the basis of "cases " rather than "specimens."

It is in the clinical subjects and in preventive medicine that English schools are most defective. The English system treats medicine too much as an art, too littrle as a science. It gives small chance for the study of prophylaxis or of incipient disease; its ward-cases are too often the "finished article." It is ill organised, for its professors are only part-time men, whose bread-winning work is their private practice, not their teaching. As an NO. 2552 , VOL. IO 2$]$ eminent physician has said: "Harley Street is the grave of the clinical teacher." "A man cannot serve two masters," says Sir George Newman. "That is the predicament of the clinical teacher in England. And there is only one solution. He must be paid as a teacher." This means, as has been pointed out authoritatively by many who have a right to speak, the establishment and endowment of whole-time professors of the "final" subjects, medicine, surgery, and obstetrics, each with his "unit" of wards, laboratories, and staff, co-ordinated, freed from the compulsion of outside practice, bound to devote himself not only to teaching, but also to research. "The need of English medicine above all others at the present time is the opportunity for the cultivation of the laboratory method and the scientific spirit." For preventive medicine the like is required; the ordinary practitioner need not be a professional or specialist medical officer of health, but he must know enough to articulate his own work with the State services that touch it at innumerable points; and he must interfuse prevention with all his curing. Hence, in his training, it is the interest of the nation to ensure that the purpose and spirit of preventive medicine should pervade the entire curriculum-for all the branches and departments of the latter need its inspiration. The General Medical Council last May took the first step along this path of progress.

"The Place of Research in Medical Schools" is the subject of a moving chapter, in which the verdict of the London University Commission (I9I3) is cited as an aphorism: "It is a necessary condition of the work of university teachers that they should be systematically engaged in original work," with the pithy comment that "he only is the great teacher who is inspired by the spirit of discovery."

The urgent need for organised and efficient "post-graduate" instruction, to enable the practitioner to supplement his general knowledge by specialities, and to keep himself abreast, by periodic study at the fountain-heads, of modern advances, is eloquently expounded, not for the first time. But it has been brought home with new insistence by the pressure of recent experience. The men of the medical services-Army, Navy, Indian, Colonial-clamour for such opportunities; graduates from the Overseas Dominions, from the United States, and from the Allied countries, are asking for the chance to study in Britain rather than in Germany or Austria. Are we ready for them in London, in England? Sir George Newman sets forth what is still lacking in our equipment, and the list of shortcomings is not small. The cost in money will be considerable: we have the men; we require the organisation. But the President of the Board of Education and "both Houses of Parliament" are told frankly that "it would handsomely repay the State to encourage and to aid " a regular system of postgraduate study, "so rapid and profound are the advances in medicine.", 
In his conclusions the author finds that, for remedial action, two fundamental necessities exist. There is the need for further financial assistance; there is the need for guidance and direction. The first implies substantial aid from the State; for the second, trust is placed in "the predominant authority of the university, . . as against the claim of proprietary interest," the State assuming only the functions of supervision and advice, "with due regard to the freedom of the university." How far such "due regard" can persist side by side with subvention and supervision it is not easy to say. But if departments and officials were endowed with Sir George Newman's knowledge, and imbued with his temper of sweet reasonableness, a way would be found of reconciling the bureaucratic and the academic points of view. That a way must be found for advance, along the lines of his vividly clear and deeply wise survey, is certain, unless England is, in the Reconstruction, to lose her opportunity and miss the lessons of her time of trial and testing.

\section{THE DYNAMICS OF CYCLONIC DEPRESSIONS.1}

THE publication in I9o6 of Shaw and Lempfert's "Life-History of Surface AirCurrents" marked the passing of a milestone in the progress of our knowledge concerning the mecharism of travelling cyclonic depressions, and it is a matter of surprise that so little further advance along the same lines has been made since that time. This lack of progress obviously could not continue for ever, and two recent publications by Sir Napier Shaw suggest that the next milestone has now been passed.

In the earlier of the two papers ${ }^{2}$ a travelling rotating disc of air was considered in which all the air particles had the same relative tangential velocity around the centre. This hypothesis led to valuable conclusions concerning the "secondaries" which so frequently form upon the southern side of the centre, but did not throw much light upon the cyclone as a whole. On consideration it became evident that the mathematics would be much more manageable if the disc of air were assumed to have uniform vorticity $\zeta$, so that the relative velocity $v=\zeta . r$, and, working on this assumption, valuable results have been obtained. This hypothesis implies a disc of air revolving about its centre as a solid like a cartwheel, and the "normal cyclone" considered in the present paper has within itself a circulation of this type. The air particles will trace out trochoids formed by the rolling of the disc of relative motion along the line of motion of the instantaneous centre, and, if sufficiently extended in all directions, the mass will possess intrinsically two centres, (I) a centre of instantaneous motion, or kinematic centre, about which the resultant winds shown upon the

1 "The Travel of Circular Depressions and Tornadoes and the Relation of Pressure to Wind for Circular Isobars." By Sir Napier Shaw. Meteorological Office. Geophysical Memoirs, No. 12, 1918.

2 "Revolving Fluid in the Atmosphere." Proc. Roy. Soc., A, vol. xciv., p. $34,197 \%$.

NO. $255^{2}$, VOL. IO2] map at any instant will be revolving (surface incurvature being neglected), and (2) a centre of revolving fluid or tornado centre that is, the centre of the "cartwheel "-which is found at a distance $V / \zeta$ on the right-hand side of the path of the instantancous centre, where $V$ is the velocity of travel of the depression as a whole.

The "normal cyclone" has, however, yet a third centre. If upon the pressure field of a stationary circular depression a uniform pressure gradient from N. (high) to $\mathrm{S}$. (low) be superposed, it is shown that every air particle will commence to follow its appropriate trochoid curve, and the effect will be that the depression will advance across the map from $W$. to $E$. with a speed $V$, while at the same time the system of isobars will be displaced a distance $V /(2 \omega \cdot \sin \phi+\zeta)$ to the south from the centre of instantaneous motion ( $\omega$ equals angular velocity of the earth, $\phi$ equals latitude). This centre of isobars is termed the dynamic centre, and forms the third centre of the travelling depression. As a numerical example, if the rotation of the disc be such that a velocity of $20 \mathrm{~m}$./ $\mathrm{sec}$. (gale. force) is found $200 \mathrm{~km}$. from the centre of instantaneous motion, and if the eastward speed of progression of the depression be ro $\mathrm{m}$./ $\mathrm{sec}$. in our latitude, the tornado centre will be roo $\mathrm{km}$., and the dynamic centre $45 \mathrm{~km}$., to the south of the instantaneous or kinematic centre.

Viewed in another way, the pressure system may be taken to be compounded of a set of circular isobars round the tornado or "cartwheel " centre, and a uniform pressure gradient from $\mathrm{S}$. to $\mathrm{N}$., when the rate of advance $V$ of the depression will equal the geostrophic wind corresponding with this field. Since this superposed field may reasonably be taken to be the same as the general field surrounding an isolated cyclonic depression, the conclusion is reached that the speed of progression of such a depression will depend directly upon the strength of the surrounding field, and in certain examples shown this is satisfactorily confirmed. One of the most interesting results reached is undoubtedly that the winds shown on a map for an eastward moving depression will circulate, not about the isobaric centre, but about a point to the north which may be of the order of $50 \mathrm{~km}$. distant. Practical examples of this are also adduced. Other conclusions of importance, such as the probability of secondaries developing at the tornado centre, cannot be more than alluded to in a short notice like the present. The demonstration of the fact that a normal travelling cyclonic depression has three distinct "centres" is the outstanding feature of the paper.

To the reader the treatment appears a little disjointed and to lack mathematical sequence, but the author has forestalled criticism on this point by explaining that he considered it better to set out the matter in the order in which it was developed, since this method would bring directly under review the various aspects of the subject that are presented to the student of weather maps. A straightforward theoretical discussion would lack this advantage. 